\title{
To Explore the Loneliness as It Related To Personality Traits among Emerging Adults Studing Medicine
}

\author{
Bhawna Chauhan $^{1 *}$, Dr Sunil Sharma ${ }^{2}$
}

\section{ABSTRACT}

Emerging Adulthood studying medicine, between the age of 18 and 25 as, a distinct developmental stage extending from adolescence to young adulthood. In literature, there is any study which includes the relationship between emerging adult's loneliness and personality traits. Therefore, the relationship between emerging adults studying medicine loneliness and personality traits has to be investigated. This study examines the association between personality traits in terms of Neuroticism (N), Extraversion (E), Openness to experience (O), Agreeableness (A) and conscientiousness (C) and loneliness among emerging adults studying medicine. A total of 100 (50 boys and 50 girls) emerging adults completed the NEO-Five factor inventory (NEOFFI) and the loneliness scale. Correlation Analysis showed that three Big five personalities dimension which Neuroticism (positively) and extraversion and agreeableness (negatively) correlated emerging adult's loneliness. Further, t-test result showed that there is a significant difference in boys and girls studying medicine on loneliness, neuroticism, extraversion and agreeableness, whereas openness and conscientiousness the results showed no significant difference between two groups.

Keywords: Loneliness, Personality Traits, Emerging Adults, Studing Medicine

There is a general consensus that over the past two decades, social, economic and demographic changes have altered the life course trajectories of young people between their early teens and late twenties. (Arnett 2006a) and becoming an adult takes longer time today than in previous decades (Arnett 2004) due to changes in life conditions change the life phases. During the last 50 years, there have been changing trends in the transition to adulthood and rules of individuals especially 18-29 years old (Arnett 2003). The changing trends in the transition to adult hood especially in the developed countries led to new conceptual motions as well. The most influential one is probably "emerging adulthood" which is characterized by young people's exploration of various possibilities in love, work and identity (Arnett 2000).

Emerging adulthood, between the ages of 18 and 25, as a distinct developmental stage extending from adolescence to young adulthood and it may not be a universal period; thus, it may vary

\footnotetext{
${ }^{1}$ Research Scholar, Himachal Pradesh University

${ }^{2}$ Asst professor, Himachal Pradesh University

*Corresponding Author

(C) 2015 I B Chauhan, S Sharma; licensee IJIP. This is an Open Access Research distributed under the terms of the Creative Commons Attribution License (http://creativecommons.org/licenses/by/2.0), which permits unrestricted use, distribution, and reproduction in any Medium, provided the original work is properly cited.
} 
across cultural groups. The main distinguish features of emerging adulthood are: (i) it is the age of identity explorations, of trying out various possibilities, especially in love and work (ii) the age of instability (iii) the most self-focused age of life (iv) The age of feeling in-between, in transition, neither adolescent nor adult and (v) the age of possibilities, when people have an unparallel opportunity to transform their lives. During the emerging adulthood years, young people must accomplish some important developmental tasks. In general, the ages between 18 and 25 are a period of completing school, establishing occupations, and creating new households (Cheah and Nelson, 2004). During these years, young people become less dependent on their parents and become gradually an adult (Arnett 2006b) and must obtain education beyond high school to attain employment sufficient to support themselves and any dependents. In addition, young people develop the social skills during this period of time (Arnett, 2007a). These developmental tasks may bring "loneliness" which is very influential on emerging adult's daily life in its wake. Loneliness, a common psychological problem, is typically defined as the unpleasant experience that occurs when person's network of social relationships is deficient in some important way, either qualitatively or quantitatively; can be linked to anxiety, reduced social competence and suicide risk (Cacioppo, Hawkley, Berntson, Ernst, Gibbs, Stickgold and Hobson, 2002).

The effect of loneliness is very adverse. Sometimes, it becomes a serious, life threatening condition. It is a major risk factor in artery erosion, high blood pressure, and stress-related conditions such as heart disease, hypertension, obesity and stroke. Loneliness can play a part in alcohol or drug use in emerging adults. A lack of social connection is directly linked to several forms of anti-social, social isolation, delinquent behavior and self-destructive behavior most notably. In both child and adults, loneliness often has a negative impact on learning and memory. It can have deviating effect on sleep patterns, and thus on the ability to function in everyday life. Personality traits are stable and highly important compositions in people's life (Mc Crae, John, 1992).

Personality traits may effect on perceived support from social relationships, and also individual loneliness. Since personality is the one psychological concept which embraces all functions of the individual has become the basic integrating concept of psychology. Each theory or school of psychology gives a different approach to the personality, yet all agree in placing it as the keystone in the study of psychology. The very comprehensive nature of personality makes it inevitable that different investigations approach it in different ways. The individual reveals his personality through purposive acts, ambitions and life plans and also through his feelings, physique, skills, interests, habits his ideas about himself about his out ward appearance. It is also reveals as, the manner in an inner life as personality is organized psychologically in an inner organization of emotion, value and beliefs which determine ones effectiveness with other individuals (Baron, Byrne and Kantowitz, 1977).

One important consideration when describing loneliness is that of individual differences Dominant theoretical approaches within the field all emphasize the value of personality 
characteristics in explaining the unpleasant experience of loneliness and the associated deficiencies of lonely persons, social relationships. Drawing on psychodynamic theory, the social needs approach (Fromm-Reichmann, 1959 and Sullivan, 1953) argues that loneliness arises from an inability to fulfill social relationships due to personality traits and intrapsychic conflicts. The aforementioned are assumed to be formed by early childhood experience with parents who failed to satisfy the child's basic needs of human intimacy. The interactionist approach agrees that loneliness arises from inter play between personality factors (e.g. extraversion), cultural factors and situational factors (Weiss, 1973, Weiss, 1982). Both the social needs approach and the interactionist approach is related to Bowlby's (1969, 1973) attachment theory, which has inspired studies that have associated loneliness in adolescence and adulthood with disrupted or insecure attachment styles (Di Tommaso, Brannen-McNulty, Ross, and Burgress, 2003: Hecht and Baum, 1984). Finally, the cognitive approach views loneliness as the result of a discrepancy between the interpersonal relationships, which one perceives they have, and the interpersonal relationships which one wishes to have (Peplau, Miceli, and Morasch, 1982). This approach additionally highlights low self-esteem and an internal, stable attribution style as predictors of loneliness.

Many researchers pointed out that loneliness is experienced more intensively in adolescence rather than the other developmental stages of life (Russell, Cutrona, Rose and Yurko, 1984).Researchers of adolescent's loneliness showed that loneliness is related with depression and low self-esteem, loneliness is linked with suicide and, adversely correlated with life satisfaction, academic failure, alcohol or drug use, and social isolation, low peer acceptance, peer rejection, self-disclosure, and intimacy. In adulthood, loneliness is associated with the lack of ability to develop intimate relationships (Wittenberg and Reis, 1986).

The importance of personality characteristics in loneliness gains support form a wealth of studies. In line with other researchers (Asendorpf and Van Aken, 2003), studied distinguished between stable core personality characteristics and less stable surface personality characteristics. The result has repeatedly related two main core personality characteristics to loneliness: extraversion and neuroticism (Hamburger and Ben-Artzi, 2003). Studies with adolescent samples that have investigated loneliness and the two personality components typically find effect sizes in the range of .09 to .25(Asendorpf and van Aken, 2003; Neto and Barros, 2000; Wilson, Sibanda Sibanda, and Wilson, 1989).A meta-analysis of 30 adolescent samples (Mahon et al., 2006) indicated that the relationship between self-esteem and loneliness were in the range of a high medium effect size within this age group. Upadhayay and Khokhar (2006) in this study aim to know the effect of personality traits on the perception of perceived loneliness in unemployed youths. The clear demarcations were observed in the groups of different levels of personality traits on perceived loneliness.

In a recent study (Cacioppo et al., 2006), negative mood, anxiety, anger optimism, self -esteem and social support were all associated with loneliness independent in undergraduate students. However, in the same study, avoidant thinking, positive effect, fear of negative evaluation, and 
social skills failed to be associated with loneliness when the personality variables served as covariates, indicating that the extent to which loneliness in functionally independent of personality may vary in relation to different affective, cognitive and behavioral features.

Studies have been shown that males and females have different social needs and friendship structure (Inderbitzen - Pisaruk, Clark and Salona, 1992). For instance, adolescent's girls have more intimate friendships than boys. These findings show that there may be gender difference in the variables that are associated with adolescent's loneliness. (Inderbitzen Pisareek et al., 1992) found that self-esteem, social skills and non-interpersonal controllability predicted loneliness in boys, where as social anxiety, social skills and interpersonal stability predicted loneliness in girls. Also, research has reported that male college students report a greater association between loneliness and negative self-perceived likeability than that reported by females(Schultz and Moore ,1986).Moreover, some studies suggest that there is a greater association between loneliness and distress (e.g. mild depression and psychosomatic complaints)among male than female adolescents (Koenig and Abram 1999). Studies that have investigated gender differences in the relationships between loneliness and extraversion and neuroticism have revealed inconclusive results (Saklofske, Yackulic and Kelly, 1986; Soklofske and Yackulic, 1989).

In a nutshell, studies that compare the different impact of personality characteristics on gender and loneliness are rare and inconclusive. These two main subjects are important not only for adolescent's life but also emerging life. The present study is to explore the loneliness as it related to personality traits in terms of Neuroticism $(\mathrm{N})$, Extraversion (E), Openness to experience (O), Agreeableness (A) and Conscientiousness (C) among emerging adults studying medicine.

\section{AIMS AND OBJECTIVES:}

The present study is an attempt to explore the loneliness as it related to personality traits in terms of Neuroticism (N), Extraversion (E), Openness to experience (O), Agreeableness (A) and Conscientiousness $(\mathrm{C})$ among emerging adults studying medicine and the study has the following objectives:

- To see the relationship of loneliness and personality traits in terms of Neuroticism, Extraversion, Openness to experience, Agreeableness and Conscientiousness.

- To see the difference among boys and girls on the variables i.e. loneliness, Neuroticism, Extraversion, Openness to experience, Agreeableness and Conscientiousness.

\section{Design:}

In the present study, correlation design was used in order to explore loneliness among emerging adults studying medicine and to see the relationship of loneliness with personality traits in terms of Neuroticism (N), Extraversion (E), Openness to experience (O), Agreeableness (A), conscientiousness (C). Further, T-test was computed to see the significant difference between girls and boys studying medicine on these variables. 


\section{Participants:}

In total hundred participants constituted the sample 50 boys and 50 girls of age 18-25 years studying medicine in Indira Gandhi Medical College (IGMC) Shimla and Medical College Tanda selected for the present study who gave their consent to participate in the present study.

\section{Tools Used:}

In this present study, loneliness scale was developed in English following the line of Asher et al, 1984. To assess the personality traits i.e. Neuroticism, Extraversion, openness to experience, Agreeableness and conscientiousness Big five inventory (NEO-FFI) used, developed by costa and Mc Crae in (1992).

\section{RESULTS}

The result of the present study showed that:

- The scores of Neuroticism are significantly and positively correlated with the scores of Loneliness in both the groups of boys and girls as well in the whole sample of emerging adults studying medicine.

- Whereas the scores of extraversion are significant but negatively correlated with the scores of loneliness in both the groups of boys and girls and in the whole sample of emerging adults studying medicine.

- The result also showed the significant and negative correlation between the scores of agreeableness and loneliness in the boys and as well in the total sample but no correlation has emerged between the scores of agreeableness and loneliness in the girls of emerging adults studying medicine.

- No significant correlation has emerged between openness and loneliness and as well as between Conscientiousness and loneliness in both the groups of boys and girls and in the whole sample of emerging adults studying medicine.

- The result also showed the significant difference between boys and girls on their scores of loneliness, Neuroticism, Extraversion, Agreeableness.

- There is no significant difference observed on the scores of boys and girls on Openness and Conscientiousness between both the groups.

\section{DISCUSSION}

Correlation Analysis results showed that Neuroticism is positively and significantly correlated with loneliness in boys, girls and as well as total sample studying medicine. This showed Neuroticism is significantly and positively related to loneliness. Further, the result of t-test showed that there is significant difference between boys and girls on the score of Neuroticism and as well as on loneliness and the mean value of neuroticism and loneliness is higher in case of girls than boys. This has resulted in higher loneliness among girls then the boys as they have higher score on neuroticism then boys. This conforms the direct relationship of loneliness and neuroticism i.e. higher the neuroticism higher the loneliness. The results of earlier studies corroborate the result of present study directly and indirectly. Atak (2009) study examines the 
association between neuroticism and loneliness among Turkish emerging adults. The results showed that neuroticism is positively and moderately correlated with loneliness. Eysenck and Eysenck (1975) women tend to score higher than man on Neuroticism. Cacioppo et al., (2006) studied negative mood, anxiety, anger, optimism, self esteem and social support were all associated with loneliness. Thus, results conforms that neuroticism is significantly and positively related to loneliness among emerging adults studying medicine.

The correlation Analysis results further revealed a significant correlation of Extraversion with loneliness, but the magnitude of direction is negative in case of boys, girls and as well as in total sample studying medicine. This show that extraversion is significantly and negatively related to loneliness. In addition the result of t-test revealed a significant difference between boys and girls on Extraversion and loneliness. The mean value of extraversion is higher in case of boys than girls but the mean value of boys is lower in case of loneliness than the girls. This shows that higher extraversion is indicating lower loneliness among boys than the girls and lower extraversion indicating higher loneliness among girls than the boys. Thus, showing higher the extraversion lower the loneliness among boys and lower the extraversion higher the loneliness in girls. Hence, conforms the negative correlation of loneliness and Extraversion among emerging adult studying medicine. The results do find support from the earlier evidence directly or indirectly. Asendorf and Van Aken (2003) study distinguished stable core personality characteristics and less stable surface personality characteristics. The result has repeatedly related two core personality traits Extraversion and neuroticism characteristics to loneliness. In an undergraduate study using multiple regressions but the independent contribution of neuroticism was larger than of extraversion (Stoke 1985). The relationship between extraversion and loneliness has been found to be mediated by social networks variables indicating that extraverts are less lonely because they have large networks. Thus, conforms that extraversion is significantly and negatively related with loneliness among emerging adults studying medicine.

In Agreeableness the Correlation Analysis result showed negative and significant correlation with loneliness in boys and total sample studying medicine but the relationship has not come out significant in case of girls. Further, t-test result showed that a significant difference in boys and girls on Agreeableness and the mean value of agreeableness in higher in boys than girls whereas, the mean value of loneliness is higher in girls than boys. Thus, showing higher the agreeableness lower the loneliness among boys and lower the agreeableness higher the loneliness in girls. Hence, the result of present study indicates agreeableness is negatively and significantly related to loneliness in case of boys and total sample. The results do find support from the earlier evidence directly or indirectly. Atak (2009) studied the association between Agreeableness and loneliness Capsi (2000) studied lonely people may have less rewarding interaction with may have less extensive social network from which they receive support and girls have less social network then boys. Therefore, extraversion and agreeableness may influence loneliness negatively by allowing more effective use of social support as a coping strategy. Hence, 
conforms that agreeableness is negatively and significantly related with loneliness among emerging adults studying medicine.

The co relational Analysis result showed that openness to experience and conscientiousness is not significantly correlated with loneliness in boys, girls and total sample studying medicine. Further, there is no significant difference found in boys and girls on openness to experience and conscientiousness. Thus, this shows that openness to experience and conscientiousness are not related with loneliness among emerging adults studying medicine.

Hence, result of the present study conforms that Neuroticism is significant and positively related to loneliness among emerging adult's studying medicine whereas the extraversion as well as agreeableness is significantly and negatively related with loneliness among emerging adult study medicine. And there is significant difference between boys and girls on Neuroticism, Extraversion, agreeableness and as well as loneliness among emerging adults studying medicine. There can be possible explanations as to why extraversion and agreeableness demonstrated a significant negative relationship with loneliness, and neuroticism demonstrated a significant positive relationship with emerging adult's loneliness in this study. People who were reporting high levels of neuroticism, a trait defined by its lack of emotional stability and optimism and noted by high levels of guilt proneness, psychosomatic concerns and worry, may be expected to describe higher level of loneliness. As regards this expectation, it was found that people higher in neuroticism experienced more negative emotions in a longitudinal study (Diener and Diener 1995). Briefly, it can be said that people who are extraverts and agreeable can feel themselves less lonely than the others; and also people who are more neurotic feel more loneliness than other (Costa and Mc. Crae 1980). Inderbitzen - Pisaruk, Clark and Salana, 1992. For instance, adolescent's girls have more intimate friendships than boys. These findings show that there may be gender difference in the variables that are associated with adolescent's loneliness. (Inderbitzen Pisareek, Clark and Solana 1992) found that self esteem, social skills and noninterpersonal controllability predicted loneliness in boys, where as social anxiety, social skills and interpersonal stability predicted loneliness in girls.

"Instability" is one of the most important features of emerging adulthood stage (Arnett 2000). The exploration of emerging adults and their shifting choices in love and work make emerging adulthood an exceptionally full and intense period of life but also an exceptionally unstable one. The best illustration of the instability of emerging adulthood is in how often they move from one residence to another. It makes emerging adulthood an unstable time, but it also reflects the explorations that take place during the emerging adult years. Emerging adults rarely know where they will be living from one year to the next. This instability may bring neuroticism, thus loneliness in its wake in emerging adulthood. In emerging adulthood years, people have a life plan, and these plans may change plenty of times during the emerging adulthood. For instance, emerging adults move in with a boy friend or girl friend and start to think of the plan as founded on their future together, only to discover that they have no future together. These changes are a 
natural consequence of their explorations; and the instability of emerging adulthood is not easy for them. In emerging adulthood stage, the problems of adolescence diminish, but instability replaces them as a new source of disruption (Arnett 2003). Generally, judging from the results, it can be said that these features of emerging adulthood may affect loneliness in emerging adulthood.

Loneliness fills emerging adults with so many negative emotions like anger, anxiety, bitterness, boredom, depression, embarrassment, fear, guilt, frustration, hate, Jealousy, panic, self-pity and suffering and these consequence further lead into psychoses, manic depression, conduct disorder etc and they start indulging in so many crimes like robbery, physical fights, alcohol and drug abuse etc. So there is a need to look over loneliness seriously to save the present and future of such emerging adults. Hence there is a high need to study loneliness and to understand loneliness and its impact on the emerging adults, who are the future of the nation and society at large.

\section{BIBLIOGRAPHY}

Arnett, J.J. (2000).Emerging Adulthood: A Theory of development from the late teens through the twenties. American Psychologist, 55,469-480.

Arnett, J.J. (2003). Conceptions of the Transition of Adulthood among emerging adults in American Ethic Groups. In J.J.Arnett and N.L.Galambo (End). New Directions for child and Adolescents Development: Exploring cultural conceptions of the Transition to Adulthood, 100, 63-67. Son Francisco-Jossey-Bass.

Arnett, J.J. (2004).Emerging Adulthood: The winding Road from late Teens through the Twenties. (First edition). New York: Oxford University Press.

Arnett, J.J. (2006a).Emerging Adulthood in Europe: A response to Bynner. Journal of Youth Studies, 9, 111-123.

Arnett, J.J. (2006b). Suffering, Selfish, Slackers? Myths and Reality about Emerging Adults. Journal of Youth and Adolescence, 36, 23-29.

Arnett, J.J. (2007a). Emerging Adulthood. What is it, and what is it good for? Child development Perspectives, 1(2)68-73. Asendorpf, J.B., and Van Aken, M.A.G (2003). Personality relationship transaction in adolescence: Core versus surface personality characteristics. Journal of Personality. 71, 629-666.

Asher, Sr., Hymel, S. and Renshew, P. (1984). Loneliness in children. Child development, 55, $1456-1464$.

Asher, S. and Coie, J. (1990). Peer rejection in childhood. New York: Cambridge University Press.

Atak Hasan (2009). Big five traits and loneliness among Turkish Emerging adults International Journal of Psychological and Behavioral Sciences, 1:2.

Baron, A.Byrne,D., and Kantowitz., B. (1977). Psychology: Understanding behavior. Baston, Allyn and Bacon.

Bowlby, J. (1973). Attachment and loss: Volume-2: Separation, anxiety and anger. London: Hogarth Press Cacioppo, J.T.Hawkley, L.C: Berntson, G.G., Ernst, J.M., Gibbs, A.C, 
Stickgold, R.,and Hobson, J.A(2002). Lonely days invade their night: Social modulation of sleep efficiency. Psychological science, 13,385-388.

Cacioppo, J.T., Hawkley, L.C., Enst, J.M., Berntson, M., Berntson, G.G., Nouriant, B., and spiegal, D. (2006). Loneliness within a nomological net: An evolutionary perspective. Journal of Research in Personality, 40, $1054-1085$.

Caspi, A. (2000). The child is the father of the man. Personality continuities from childhood to adulthood. Journal of Personality and Social Psychology, 78, 158-172.

Cheah,C.S.L., Nelson, J.S. (2004). The Role of Acculturation in the Emerging Adulthood of Aboriginal College Students. International Journal of Behavioral Development, 28(6), $495-507$.

Costa, P.T., Jr., and Mc Crae, R.R. (1980a). Influence of extraversion and Neuroticism on subjective well-being: Happy and unhappy peer. Journal of behavioral Medicine, 3, 245 257.

Deiner, E. and Diener, M. (1995). Cross cultural correlates of life satisfaction and self Esteem. Journal of Personality and Social Psychology, 68, 653-663.

Di TommAso, E., Brannen - Mc Nulty, C. Ross, L., and Burgess, M. (2003). Attachment styles, social skills and loneliness in young adults. Personality and Individual Difference, 35, $303-312$.

Eysenck, H.J. and Eysenck S.B.G. (1975).Manual of the Eysenck Personality Questionnarie. San Diego : EdITS Publishers.

Fromm - Reichmann, F. (1959). Loneliness Psychiatry, 22, 1 - 15

Hamburger-Amichai and BenArtzi.E (2003). Loneliness and Internet use. Computer in Human Behavior, 19, 71-80

Hecht, D.T. and Baum, S.K. (1984). Loneliness and attachment patterns in young adults. Journal of Clinical Psychology, 40, 193 - 197

Inderbitzen - Pisaruk, H. Clark, M.L., and Salana C.H. (1992). Correlates of loneliness in mid adolescence, Journal of Youth and Adolescent, 21, 151 - 167

Koenig, L.T and Abram, R.F. (1999). Adolescent Loneliness and adjustment: A focus on gender difference. In K.J.Rotenberg and S. Hymel (Eds.). Loneliness in Childhood and adolescence, 296 - 322. New York: Cambridge University Press.

Mahon, N.E., Yarckeshi, A., Yarcheski, T.J., Cannella, B.J., and Hanks, M.M. (2006). A meta analytic Study of predictors for loneliness during adolescence. Nursing Research, 55, 308 -315 .

Mc Crae, R.R., and Costa, P.T., Jr. (in press - a). Conceptions and Correlates of openness to experience. In S.R.Briggs, R.Hogan and W.H.Jones (Ed). Handbook of personality Psychology. New York : Academic Press.

Mc. Crae, R.R., and John. O.P. (1992). Introduction to the five model and its applications. Journal of Personality , 60, $175-215$.

Peplau, L.A., Perlman, D. (1982). Perspectives on loneliness. In L.D.Peplau and D.Perlman and D.Perlman (Eds), Loneliness: A sourcebook of current theory, research and therapy (135 -151). New York: Wiley. 
Russell, D Cutrona, C.E.Rose, and Yorko, K. (1984). Social and emotional loneliness: An examination of weiss's typology of loneliness. Journal of Personality and social Psychology, 46, 1313-1321

Saklofske, D.H. and Yackulic ,R.A. , and Kelly, I.W.(1986). Personality and loneliness. Personality and Individual difference, 7, 899-901.

Saklofske, D.H. and Yackulic ,R.A. (1989). Personality Predictors of loneliness .Personality and Individual differences, 10, $467-472$

Schultz, N.R., and Moore, D. (1986). The loneliness Experience of College students Sex differences. Personality and social Psychology Bulletin, 12, 111-119.

Stokes, J.P. (1985). The relation of social Network and individual difference variables to loneliness. Journal of Personality and social Psychology, 48, 981 - 990.

Sullivan, H.S. (1953). The interpersonal theory of Psychiatry. New York: W.W.Nerton.

Upadhayay Brijesh Kumar and Khokhar, C.P. (2006). Personality Traits and Feeling of Loneliness in unemployment youths. Europe's Journal of Psychology.

Weiss, R. (1973). Loneliness: The experience of emotional and social isolation. Cambridge $M$ A: MIT Press.

Weiss, R (1982). Issue in the study of loneliness. In L.Peplau and D. Perelman (Eds.), Loneliness: A source book of current theory research and Therapy, $71-80$. New York: Weley.

Wilson, D., Sibanda, J., Sibanda, P., and Wilson, C. (1989). Personality Concomitants of loneliness among black and white male Zimbabwean adolescents. Journal of Social Psychology, 129, 577 - 578.

Wittenberg, M.T. and Reis, H.T. (1986), Loneliness, Social Skills and Social Preception. Personality and social Psychology Bulletin, 12, $121-130$. 